Gregório Corrêa

GUIMARÃES ${ }^{1}$

Márcia Rita Fernandes

$\mathrm{MACHADO}^{1}$

André Luiz Quagliatto

SANTOS ${ }^{2}$

Maria Angélica MIGLINO3

Correspondência para:

GREGÒRIOCORRÊA GUIMARÃES

Departamento de Morfologia e Fisiologia Animal

Faculdade de Ciências Agrárias e Veterinárias

Universidade Estadual Paulista

Via de Acesso Professor Paulo Donato

Castellane, $\mathrm{s} / \mathrm{n}$

14884-900-Jaboticabal-SP

gregorio@fcav.unesp.br

Recebido para publicação: 28/02/2005 Aprovado para publicação: 13/02/2006

\title{
Anatomia do músculo abdutor crural caudal do gato doméstico (Felis catus domesticus, Linnaeus 1758)
}

1 - Departamento de Cirurgia Veterinária da Faculdade de Ciências Agrárias e Veterinárias da Universidade Estadual Paulista, Jaboticabal - SP 2 - Faculdade de Medicina Veterinária da Universidade Federal de Uberlândia - MG

3 - Departamento de Cirurgia da Faculdade de Medicina Veterinária e Zootecnia da Universidade de São Paulo, São Paulo - SP

\section{Resumo}

A morfologia e a freqüência da ocorrência do músculo abdutor crural caudal foram estudadas em 58 gatos adultos, sem raça definida, 36 fêmeas e 22 machos. Após a dissecção, encontrou-se uma freqüência de $98,3 \%$ para a presença do referido músculo, o qual se apresentou simetricamente em 35 fêmeas $(97,2 \%)$ e nos 22 machos $(100,0 \%)$. Quando presente este músculo originava no processo transverso da primeira vértebra caudal, na região glútea, sob o músculo glúteo superficial, posicionando-se longitudinalmente, por quase toda a extensão da coxa, sob o músculo bíceps femoral, paralelamente ao nervo isquiático, do qual recebia ramos nervosos em 78,3\% dos casos. A largura e a espessura do ventre do músculo abdutor crural caudal apresentaram, respectivamente, média de $2,03 \mathrm{~mm}$ e $0,35 \mathrm{~mm}$. Sua inserção ocorria no ventre do músculo bíceps femoral próximo a fáscia crural, onde esses dois músculos se fusionavam.

\section{Introdução}

A maior parte dos músculos da cabeça, tronco e membros do gato, se assemelha aos seus correspondentes no cão, tanto na sua posição quanto em sua ação. Estes músculos, classificados como estriados esqueléticos, apresentam simetria bilateral e são controlados por nervos de ação voluntária ${ }^{1}$.

Particularmente ao músculo abdutor crural caudal, objeto deste estudo, se apresenta como uma longa e estreita tira muscular, medindo no cão aproximadamente 10 a $12 \mathrm{~mm}$ de largura e $1 \mathrm{~mm}$ de espessura ${ }^{2}$. Situa-se profundamente ao músculo bíceps femoral e é encontrado somente nos carnívoros ${ }^{3,4,5}$. É um músculo de ocorrência tão rudimentar no gato ${ }^{4}$ que às vezes fica difícil identificá-lo $\mathrm{l}^{5,6}$.

No gato origina-se por meio de um fino e achatado tendão, na face profunda da aponeurose do músculo bíceps femoral, distalmente, no ligamento sacrotuberal, próximo à tuberosidade isquiática ${ }^{6}$, origem esta, também observada no cão.

Nos carnívoros, o músculo abdutor crural caudal estende-se sob os dois ventres do músculo bíceps femoral e sobre a face lateral dos músculos quadrado femoral, adutor e semimembranoso, quase que paralelo ao nervo isquiático ${ }^{2,4,6,7,8}$. Dyce, Sack e Wensing ${ }^{9}$. Sissan e Grossman ${ }^{7}$ acrescentam que suas fibras derivam do músculo bíceps femoral.

No cão o músculo abdutor crural caudal se torna visível caudalmente, pois na região do linfonodo poplíteo não está totalmente coberto pelo músculo bíceps femoral $^{8}$. Sua inserção ocorre na fáscia crural, junto com as fibras mais caudais do músculo bíceps femoral ${ }^{3,8}$, às quais se fusionam ${ }^{4,5,7}$. De acordo com Harrison ${ }^{6}$ às vezes essa fusão não é notada no gato.

O músculo abdutor crural caudal do cão e do gato possui dimensão reduzida e, 
juntamente com o músculo bíceps femoral, participa, embora em menor intensidade, da função de abdução do membro pélvico ${ }^{2,3,4,5,8,9}$. Quanto à sua inervação, suas fibras musculares são supridas por ramos provenientes do nervo isquiático ${ }^{2,9}$.

Uma vez que na literatura consultada se observa um maior número de informações sobre o músculo abdutor crural caudal do cão, se propôs no presente trabalho estudá-lo mais detalhadamente no gato doméstico, mediante a descrição da freqüência de sua distribuição, da identificação de seus tendões de origem e de inserção, da determinação da espessura e da largura de seu ventre muscular, bem como, do estabelecimento de sua inervação, visando observar neste músculo caracterís-ticas específicas e comuns inerentes a essas espécies.

\section{Materiais e Métodos}

Foram utilizadas 58 peças de gatos adultos, sem raça definida, 36 fêmeas e 22 machos, as quais já haviam sido utilizadas em experimentos conduzidos anteriormente no Laboratório de Anatomia da FCAV/ UNESP.

As peças, que já estavam fixadas e acondicionadas em solução de formaldeído a 10\%, foram dissecadas mediante realização de duas incisões iniciais, uma transversal, na pele do terço médio da perna e outra vertical, na pele da face medial da coxa, ligando a porção mais proximal do membro pélvico, onde se iniciava, até a incisão anterior e assim, rebatia-se a pele de toda essa região. Em seqüência, incisou-se a pele, contornando a raiz da cauda, o ânus e os órgãos genitais externos, rebatendo-se a pele, bem como as fáscias subcutâneas relativas às regiões glútea, coxa e parte da perna.

Os músculos glúteo superficial e o glúteo femoral foram individualizados mediante divulsão transversal e rebatidos dorsalmente. Em seguida o músculo bíceps femoral foi separado de sua inserção na fáscia lata e crural, seccionado transversal- mente, no nível da articulação fêmur-tíbiopatelar e rebatido caudalmente, permitindo a identificação do músculo abdutor crural caudal.

Assim pode-se observar a freqüência de ocorrência do músculo em questão e, ao constatar-se sua presença, identificava-se seu suprimento nervoso e seus tendões de origem e de inserção com as estruturas adjacentes. Também se efetuou a mensuração da espessura e da largura de seu ventre muscular, na altura do terço média da perna, com o auxílio de paquímetro digital Starrettâ.

A nomenclatura adotada para este estudo estava de acordo com o International Committee on Veterinary Gross Anatomical Nomenclature $^{10}$.

\section{Resultados}

O músculo abdutor crural caudal foi encontrado em 98,3\% dos animais estudados, nos dois antímeros de 35 exemplares de fêmeas $(97,2 \%)$, e bilateralmente nos 22 exemplares (100,0\%), dos machos.

Quando presente, o músculo abdutor crural caudal originava-se no processo transverso da primeira vértebra caudal (Figura 1), na região glútea, sob o músculo glúteo superficial, posicionando-se longitudinal-mente, por quase toda a extensão da coxa, continuando-se sob o músculo bíceps femoral, paralelamente ao nervo isquiático (Figura 2), o qual lhe enviava ramos nervosos em 78,3\% dos exemplares (sendo, em 83,3\% dos casos, no antímero direito e em $73,3 \%$ no antímero esquerdo).

O músculo abdutor crural caudal apresentava sintopia com a face profunda dos músculos glúteo superficial, glúteo femoral e bíceps femoral e com as faces laterais dos músculos gêmeos, obturador interno, quadrado femoral, adutor e semimembranoso (Figura 2).

Quanto à largura do músculo abdutor crural caudal, encontrou-se os valores mínimo e máximo, no antímero esquerdo, de 1,23 e $2,08 \mathrm{~mm}$, respectivamente e no 


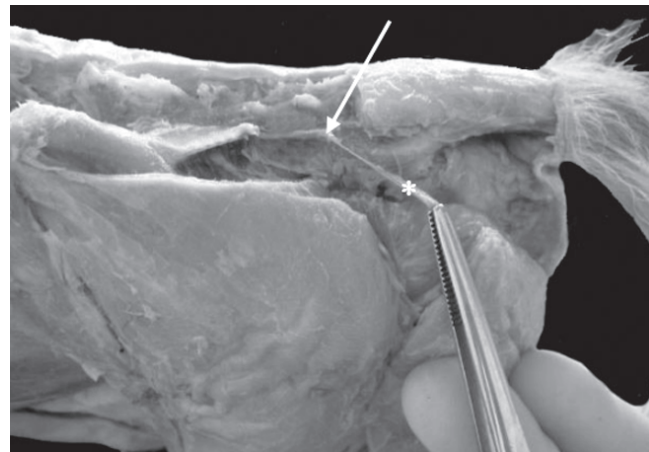

Figura 1 - Fotografia da origem (seta) do músculo abdutor crural cauda (*) de um gato adulto, a partir do processo transverso da primeira vértebra caudal (seta)

direito, 1,23 e 3,59 $\mathrm{mm}$, respectivamente, com valor médio entre os dois antímeros de 2,03 \pm 0,46 (desvio padrão). A espessura do ventre muscular variou de 0,21 à 0,49 $\mathrm{mm}$ no antímero esquerdo e de 0,19 à 0,56 $\mathrm{mm}$ no antímero direito, obtendo-se valor médio de $0,35 \mathrm{~mm} \pm 0,08$ entre os dois antímeros.

A inserção do músculo abdutor crural caudal ocorria junto ao ventre do músculo bíceps femoral, próximo à sua fáscia crural em 100,0\% dos casos, onde os dois músculos acabavam se fusionando (Figura 2).

\section{Discussão}

Conforme as descrições de Hudson e Hamilton ${ }^{1}$ sobre as semelhanças existentes entre a musculatura do cão e do gato, verificou-se nesta ocasião, que o músculo abdutor crural caudal, no gato, se apresentava de forma bem delgada, estreita e alongada ${ }^{4,5,6}$, características estas também descritas por Evans e Christensen ${ }^{2}$ para o cão.

Os valores médios, referentes à largura e à espessura do músculo ora observados foram de 2,03 $\pm 0,46$ e 0,35 $\mathrm{mm} \pm 0,08$, respectivamente, e são discrepantes das informações mencionadas para essa estrutura nos cães, aos quais são atribuídos os valores médios de $11 \mathrm{~mm}$ para sua largura e de $1 \mathrm{~mm}$ para sua espessura ${ }^{2}$. Para o gato não foram observadas, na

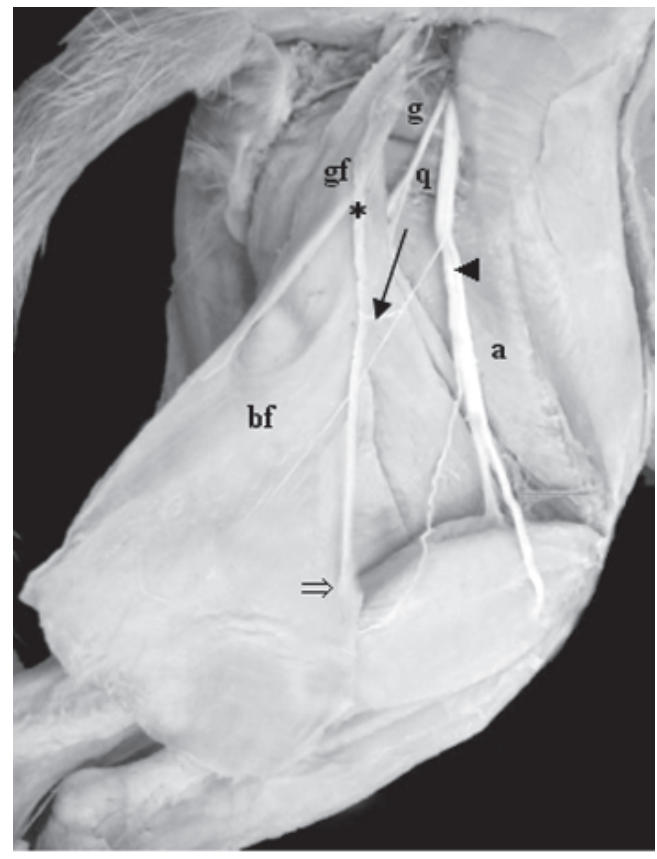

Figura 2 - Fotografia da localização do músculo abdutor crural caudal $\left.{ }^{*}\right)$ de um gato adulto, nas regiões glútea e coxa, posicionado longitudinalmente sob o músculo bíceps femoral (bf), paralelamente ao nervo isquiático(?) com seus ramos nervosos (seta), também se observa a face profunda do músculo glúteo femoral (gf), as faces laterais dos músculos gêmeos (g) e parte dos músculos quadrado femoral (q), adutor (a) e semimembranoso (s), bem como, sua inserção junto ao ventre do músculo bíceps femoral (P)

literatura consultada, dados sobre estes parâmetros e tão pouco sobre os valores referentes às mensurações do ventre desse músculo.

No gato não se observou a fixação do tendão de origem do músculo abdutor crural caudal, na face profunda da aponeurose do músculo bíceps femoral, distalmente, no ligamento sacrotuberal, próximo à tuberosidade isquiática, conforme relatos de Harrison ${ }^{6}$, para esta espécie e as descrições de Evans e Christensen $^{2}$, König e Liebich ${ }^{3}$, Nickel et al. ${ }^{4}$, Schwarze e Schröder ${ }^{5}$, Sisson e Grossman e St. Clair ${ }^{8}$ para o cão. Constatou-se nesta oportunidade, a origem deste músculo a partir do processo transverso da primeira vértebra caudal, sob o músculo glúteo superficial.

Observou-se neste trabalho que o músculo abdutor crural caudal do gato, tal 
qual o do cão ${ }^{2,4,7,8}$, apresenta situação paralela ao nervo isquiático mas, diferentemente desses animais, além da sua sintopia com os músculos bíceps femoral, quadrado femoral, adutor e semimembranoso, no gato, constata-se ainda, sua relação com os músculos glúteo superficial, glúteo femoral, gêmeos e obturador interno.

No atinente à inervação do músculo abdutor crural caudal do gato, evidenciou-se, em 78,3\% dos exemplares, a emissão de ramos a partir do nervo isquiático para este músculo, corroborando com os informes de Dyce, Sack e Wensing 9 e Evans e Christensen ${ }^{2}$ para o cão.

A inserção do músculo ora estudado ocorreu no ventre muscular do músculo bíceps femoral, próximo à fáscia crural, e não na fáscia desse músculo propriamente dita, como foi descrito para o cão ${ }^{3,8}$. Os dois músculos uniam seus ventres na região da articulação fêmur-tíbio-patelar conforme os relatos para o cão ${ }^{4,5,7}$. Também não se observou nesta ocasião, a exposição do músculo abdutor crural caudal na região do linfonodo poplíteo como relatou St. Clair ${ }^{8}$ para o cão.

\section{Conclusões}

No gato o músculo abdutor crural caudal se apresenta como uma fina, estreita e longa fita muscular, cuja origem ocorre no processo transverso da primeira vértebra caudal, sob o músculo glúteo superficial, na região glútea. Situa-se estendido em toda a extensão da coxa paralelamente ao nervo isquiático, do qual recebe ramos, sob o músculo bíceps femoral, ao qual se fusiona na altura da articulação fêmur-tíbio-patelar. A ausência notada em apenas um exemplar pode ser atribuída ao seu aspecto rudimentar.

\title{
Anatomy of the abductor cruris caudalis muscle of the domestic cat (Felis catus domesticus, Linnaeus 1758)
}

\begin{abstract}
The frequency and the morphology of the abductor cruris caudalis muscle were studied in 58 adult unknown breed cats. The sample included 36 females and 22 males. After the dissection, were found a frequency for the presence of the same muscle of $98.3 \%$. The abductor cruris caudalis muscle appears symmetrically in 35 females (97.2\%) and 22 males $(100.0 \%)$. When present, it were originated on the transversal process of the 1 st vertebrae caudales, in the glutea region, below the gluteus superficialis muscle, throughing almost all the thigh under biceps femoris muscle, where it make a parallel relation with the sciatic nerve, receiving nervous ramifications of the same in $78.3 \%$ of the cases. The medium found for the width and thickness of his muscle venter was respectively of $2.03 \mathrm{~mm}$ and $0.35 \mathrm{~mm}$. Its insertion occurs on the biceps femoris muscles approximate to the fascia cruris, where both finish fusing theirselves.
\end{abstract}

Key-words:

Abductor cruris caudalis. Muscle. Cat.

\section{Referências}

9 DYCE, K. M.; SACK, W. O.; WENSING, C. J. G. Tratado de anatomia veterinária. 3 . ed. Rio de Janeiro: Elsevier, 2004. p. 94.

2 EVANS, H. E.; CHRISTENSEN, G. C. Miller's anatomy of the dog. Philadelphia: W. B. Saunders, 1979. 1181 p. p. 384.
6 HARRISON, B. M. Disección del gato. Zaragoza: Acribia, 1969. 248 p. p. 100.

1 HUDSON, L. C.; HAMILTON, W. P. Atlas of feline anatomy for veterinarians. 1. ed. Philadelphia: W. B. Saunders, 1993. p. 40.

10 INTERNATIONAL COMMITTEE ON VETERINARY GROSS ANATOMICAL NOMENCLATURE. Nomina anatomica veterinaria. 4. ed. New York: World Association on Veterinary Anatomist, 1994. 198 p. 
(Together with nomina histologica, 2. ed., 1992 and nomina embryologica veterinaria, 1992).

3 KÖNIG, H. L; LIEBICH, H. Anatomia dos animais domésticos: texto e atlas colorido. Porto Alegre: Artmed, 2002. p. 242-243 e 247.

4 NICKEL, R. et al. The locomotor system of the domestic mammals. 2. ed. Berlin-Hamburg: Paul Parey, 1986. p. 402.

5 SCHWARZE, E.; SCHRÖDER, L. Compendio de anatomia veterinaria: introducción a la anatomía veterinaria aparato locomotor. Zaragoza: Acribia, 1970. p. 218.

7 SISSON, S.; GROSSMAN, J. D. Anatomía de los animales domésticos. 4. ed. Barcelona: Salvat, 1979. p. 361.

8 St CLAIR, L. E. Músculos dos carnívoros. In: GETTY, R. Anatomia dos animais domésticos. 5. ed. v.2, Rio de Janeiro: Interamericana, 1981. p. 1438. Título do artigo: Anatomia do músculo abdutor crural caudal do gato doméstico (Felis catus domesticus, Linnaeus 1758). 